\title{
Development of the positive-negative asymmetry effect: In-group exclusion norm as a mediator of children's evaluations on negative attributes
}

\author{
ADAM RUTLAND ${ }^{1 *}$, RUPERT J. BROWN ${ }^{2}$, \\ LINDSEY CAMERON ${ }^{1}$, ANNI AHMAVAARA ${ }^{1}$, \\ KATIE ARNOLD ${ }^{1}$ AND JENNI SAMSON ${ }^{1}$ \\ ${ }^{1}$ Centre for the Study of Group Processes, \\ Department of Psychology, University of Kent, \\ Canterbury, Kent CT2 7NP, UK \\ ${ }^{2}$ University of Sussex, UK
}

Abstract

Two studies were conducted that go beyond previous research by examining when and why children might show intergroup bias in the attribution of positive, but not negative traits (PNAE: the positivenegative asymmetry effect, Mummendey \& Otten, 1998, European review of social psychology, Vol. 9). In Study $1(n=107)$ children completed a 'mixed' trait attribution task in a dichotomous group context. As predicted there was a developmental trend between 7 and 12 years of age in the PNAE. The 7-year olds were the only age group not to show the effect. Study 1 also found a quadratic developmental trend in children's national intergroup bias. Study $2(n=62)$ replicated the developmental path of the PNAE found in Study 1 using a wider age range of 6-16 years. This study used a 'mixed' list of traits which were not only antonyms and a procedure that made the positive and negative trait dimensions explicitly independent. Significantly, Study 2 found in-group exclusion norm partially mediated the development of the PNAE. These findings support an account of the positive-negative asymmetry effect based upon normative processes. Copyright (C) 2006 John Wiley \& Sons, Ltd.

According to social identity theory (SIT: Tajfel \& Turner, 1986) intergroup bias is achieved as a result of individual's striving for positive social distinctiveness, in the context of some in-group identification and the salience of an in-group versus out-group categorization. In this account positive distinctiveness can be created independently of the valence of the attributes to be assigned. Recent research has shown that us-them categorization results in less social discrimination when negative rather than positive attributes are allocated between groups (Blanz, Mummendey, \& Otten, 1995; Buhl, 1999; Gardham \& Brown, 2001; Mummendey \& Otten, 1998; Otten, Mummendey, \& Blanz, 1996). This phenomenon has been termed the 'positive-negative asymmetry effect' (PNAE: Mummendey et al., 1992).

*Correspondence to: Adam Rutland, Centre for the Study of Group Processes, Department of Psychology, University of Kent, Canterbury, Kent CT2 7NP, UK.

E-mail: a.rutland@kent.ac.uk 
The present research examined when and why children might show intergroup bias on positive, but not negative, valence attributions. Significantly, development of the PNAE has been relatively ignored in previous research on children's intergroup attitudes. The findings of a few studies suggest children are sometimes more willing to differentiate between groups on positive attributes and much less reliably show intergroup discrimination on negative attributes (Bennett et al., 2004; Bennett, Lyons, Sani, \& Barrett, 1998; Bigler, Brown, \& Markell, 2001; Bigler, Jones, \& Lobliner, 1997). Nonetheless these studies have not systematically studied the developmental path of the PNAE across the whole age range of middle childhood into adolescence. Moreover, they have failed to identify any underlying processes that might explain the development of the PNAE. A recent study by Rutland, Cameron, Bennett and Ferrell (2005) did reveal that 3- to 5-year-old children failed to show the PNAE, since they differentiated between the in-group and out-group on both positive and negative trait attributions. Therefore, two studies will be presented that together examined the development of national intergroup attitudes from 6 to 16 years of age and addressed the mediating role of social norms in the development of the PNAE. An analysis of developmental changes in the PNAE should inform accounts of this effect within social psychology.

The normative account appears relevant to the development of children's willingness to differentiate between in-group and out-group on negative attributes (Blanz, Mummendey, \& Otten, 1997; Mummendey \& Otten, 1998). According to this account, there are usually social constraints against displaying explicitly social discrimination involving negative but not positive outcomes. This reflects the existence of a social norm against discrimination using negative stimuli (Amiot \& Bourhis, 2003; Blanz et al., 1997; Mummendey \& Otten, 1998). The emergence of the PNAE should be dependent upon children being aware of the norm regarding the social acceptability of discrimination involving negative outcomes. Indeed, a cross-national study of 6-year-old children by Bennett et al. (2004) suggests that norms embedded in a country's socio-political history may affect the onset of the PNAE. This study found children from four of the five countries studied showed some evidence of discrimination on the negative traits. However, this discrimination was particular to certain out-groups to which expressions of bias were commonplace in public discourse. For example, children from the former Soviet republic of Azeri only showed discrimination on negative traits towards the Russians, who supported the invasion of their country in 1992. In Western societies (e.g., America and western Europe) there is evidence that children are sensitive to the norm that discrimination based upon a negative outcome (i.e., exclusion) is unacceptable (see, Killen, Lee-Kim, McGlothlin, \& Stangor, 2002; Killen \& Stangor, 2001). However, research suggests children below 8 years are relatively less attentive than older children to what is normative when engaging in social reasoning about inclusion and exclusion (Abrams, Rutland, \& Cameron, 2003a; Abrams, Rutland, Cameron, \& Marques, 2003b; Rutland, 2004; Rutland, Cameron, Milne, \& McGeorge, 2005). Thus in the present study it is anticipated that children below 8 years are less likely to become aware of the norm that discrimination involving negative outcomes is socially undesirable and thus, demonstrate the PNAE.

To show the PNAE children also need to act upon their knowledge and engage in self-presentation by differentiating only on positive attributions. Developmental research indicates children as young as 5 years are cognitively capable of understanding self-presentation behavior (Banerjee \& Yuill, 1999a,b). Furthermore, research suggests children as young as 6 years engage in self-presentation when made accountable to an audience and in the context of a salient social category (e.g., Banerjee \& Lintern, 2000; Rutland et al., 2005). For example, Rutland et al. (2005) showed that under high accountability young children engaged in self-presentation when stating their explicit racial intergroup attitudes. In contrast, other studies utilizing less salient social categories and not manipulating accountability have shown children below 8 years do not spontaneously engage in self-presentational behavior (e.g., Aloise-Young, 1993; Bennett \& Yeeles, 1990). Similarly, in the present study accountability was not manipulated and the focus was on a social category (i.e., nationality) that is 
known to be relatively peripheral to the self-concept until middle childhood (Barrett, Lyons, \& del Valle, 2004). Therefore, based upon this evidence and in the context of the present research, it seems reasonable to predict only children above 8 years of age will demonstrate the PNAE because they will spontaneously engage in self-presentation.

Study 1 examined independently children's attitudes toward their own national in-group and a relevant national out-group. Unlike Bennett et al. (2004), who adopted a multi-group context (i.e., the children judged their in-group in the context of multiple out-groups); Study 1 used a dichotomous group context (i.e., the children judged their in-group and an out-group only). Bennett and colleague acknowledged that multi-group contexts are less likely to invoke discriminatory judgments compared to dichotomous group contexts. Indeed research suggests that intergroup bias is less likely in multiple compared to dichotomous group contexts (e.g., Hartstone \& Augoustinos, 1995; Wilder \& Thompson, 1988) since the existence of multiple out-group comparisons is known to reduce intergroup bias by decreasing an 'us versus them' competitive orientation. Therefore, the use of a dichotomous group context within the present research could be considered a stricter test of whether children show the PNAE.

Study 1 was also concerned with developmental trends in children's national in-group and outgroup attitudes. Research has typically found a 'peaking' of children's ethnic bias around approximately 7 years of age and then a decline in subsequent years (see Aboud, 1988; Brown, 1995; Cameron, Alvarez, Ruble, \& Fuligni, 2001; Lambert \& Klineberg, 1967). Cognitive-developmental theory (Aboud, 1988; Katz, 1976) contends that bias declines from 7 years because children's no longer over apply social categorical thinking coupled with strong emotional attachment to salient in-groups. Thus, from 7 years the children's social-categorical focus is subsequently replaced by more individuated perception with the acquisition of concrete operational thought and a more diffuse set of group loyalties, so children begin to make judgments in terms of unique interpersonal rather than intergroup qualities.

Alternatively, Rutland and colleagues (Rutland, 1999, 2004; Rutland et al., 2005) contend that the developmental decline of intergroup bias in middle childhood reflects children's increasing awareness of the generic social norm against explicit discrimination and their ability to engage in selfpresentational behavior. According to this view, bias typically declines during middle childhood with the development of an internal motivation to control prejudiced attitudes (Fazio, Jackson, Dunton, \& Williams, 1995; Plant \& Devine, 1998). Moreover, this motivation results from the internalization of and attempt to conform to perceived social norms regarding the appropriateness of explicitly expressing prejudice (Crandall, Eshleman, \& O'Brien, 2002). Despite their differing mechanisms of development, both the cognitive-developmental and the self-presentational account would predict that intergroup bias should decline in middle childhood.

Interestingly, however, there are various examples of research on children's national intergroup attitudes indicating that children in early adolescence can still show intergroup bias (e.g., Abrams et al., 2003a; Bennett et al., 1998; Rutland, 1999; Tajfel, Nemeth, Jahoda, Campbell, \& Johnson, 1970; Verkuyten, 2001, 2003; Teichman, 2001). This finding could be explained by a self-presentational account, since Rutland et al. (2005) found that when 10- to 12-year-old children were made publicly self-conscious they moderated their expression of national intergroup. However, significantly they did not inhibit their explicit bias, rather heightened public self-focus only acted to increase national ingroup bias. This suggests that while early adolescents may be aware of a generic or moral norm against discrimination their intergroup attitudes, in the context of a salient intergroup rivalry between Germany and Britain (see Abrams et al., 2003a; Barrett, Wilson, \& Lyons, 2003; Rutland, 1999, 2004; Rutland et al., 2005), may be affected by a specific ideological or social-conventional norm that legitimizes national intergroup bias (Amiot \& Bourhis, 2003, 2005a,b; Killen \& Stangor, 2001; Rutland, 1999). 
Previous studies (Bennett et al., 1998; Rutland, 1999; Verkuyten, 2001) of national intergroup attitudes have included children of many different ages ranging from 6 to 16 years. However, no study to our knowledge has examined in detail changes in children's national in-group and out-group attitudes between the crucial ages of 7 and 12 years. This is a significant age range for the cognitivedevelopmental and self-presentational accounts (see Aboud, 1988; Doyle \& Aboud, 1995; Rutland et al., 2005) because between these years children normally develop the ability to attend to individuating information (e.g., Doyle \& Aboud, 1995; Katz, Sohn, \& Zalk, 1975) and engage in selfpresentational behavior (Aloise-Young, 1993; Banerjee \& Yuill, 1999a,b; Bennett \& Yeeles, 1990). Therefore, Study 1 examined developmental trends in children's intergroup attitudes between the ages of 7 and 12 years. In line with existing research on intergroup attitudes (see Aboud, 1988; Brown, 1995) it is predicted that intergroup bias will decline significantly from 7 years of age. However, based upon previous studies of national intergroup attitudes (e.g., Abrams et al., 2003a; Bennett et al., 1998; Rutland, 1999; Verkuyten, 2001) and the self-presentational account of prejudice development (Rutland, 2004; Rutland et al., 2005), it is expected that intergroup bias will show a quadratic trend with an increase again in early adolescence.

In Study 1 white British children between 7 and 12 years were tested on a national trait attribution task, which assessed positive and negative evaluations of the British in-group and German out-group separately. Valence in the trait attribution task was given by the positivity and negativity of the traits that could be allocated to in-group and out-group. These intergroup attitude measures were designed to overcome a limitation associated with previous methods that have typically confounded in-group and out-group attitudes (Cameron, et al., 2001; Nesdale, 2001). As Cameron et al. (2001) point out, many of the methodologies traditionally used to assess children's intergroup attitudes employ a forced choice procedure in which an in-group choice implies not choosing an out-group. This procedure artificially forces a reciprocal relationship between in-group and out-group attitudes, resulting in a confound between the two attitudes. Therefore, within Study 1 children's in-group and out-group attitudes are considered separately, in addition to their overall intergroup attitudes.

In summary, all age groups in Study 1 except the 7-year olds should show the PNAE. Children aged 8 years and above should have more advanced awareness of the social norm that negative evaluation of others is unacceptable combined with an ability to spontaneously engage in self-presentation. Finally, in line with cognitive-developmental theory (Aboud, 1988) and the self-presentational account (Rutland, 2004; Rutland et al., 2005) national intergroup bias in Study 1 should decline significantly from 7 years of age. Though, intergroup bias should show a quadratic trend and increase again amongst the 11- to 12-year olds.

\section{STUDY 1}

\section{Method}

\section{Participants}

One hundred seven white British children ( 55 females and 52 females), were tested. The children came from one of four age groups: thirty-one 7-year olds ( $M=88.97$ months, $S D=2.99$ months), nineteen 8year olds $(M=101.38$ months, $S D=3.15$ months), forty 9-year olds $(M=113.75$ months, $S D=3.59$ months), and seventeen 11 - to 12 -year olds $(M=134.47$ months, $S D=4.78$ months $)$. The children lived in predominately mixed socio-economic suburban or rural areas outside a large metropolitan city. 
A very small proportion of the school population was from a visible ethnic minority and the majority of the teachers were white British.

\section{Procedure}

Participants were interviewed one-to-one by researchers for approximately 15 minutes. The interview schedule used was a modified version of the one used in the research initiative to celebrate the Centenary of the British Psychological Society [BPS Developmental Psychology Section (2001). 'Children's Views of Britain and Britishness in 2001' - http://devpsy.lboro.ac.uk/bps/project]. It involved a trait evaluation task which was used to assess attitudes towards the British in-group and the German out-group (Takriti, Buchanan-Barrow, \& Barrett, 2000). Germans were chosen as the outgroup since previous research suggests that within Britain they are salient comparison group (Mummendey, Klink, \& Brown, 2001; Rutland \& Cinnirella, 2000) and British children often hold relatively negative attitudes towards Germans (Abrams et al., 2003a; Barrett \& Short, 1992; Johnson, 1973; Rutland, 1999).

The trait evaluation task measured how typical the children thought positive and negative traits were of the British in-group and German out-group. The following set of five cards was placed in sequence in front of the child: 'none of them' (scored 1); 'a few of them' (scored 2); 'half of them' (scored 3); 'a lot of them' (scored 4); 'all of them' (scored 5). The order of the layout of the cards was reversed across successive children. The child was asked to look at the cards and the interviewer read the set of cards with the younger children. To make sure the children understood the scale presented on the cards, a few training questions were asked. Two training cards were shown to the child. The first showed ten people (eight colored red and two colored blue). The child was asked 'how many are red?' They gave their answer by pointing at one of the five cards. The same procedure was followed with a second training card, which showed five people colored red and five people colored blue.

When the child had clearly understood how to use the cards, the researcher said: 'Now, can you think about British people, and can you also think about German people? I want to ask you some questions about British and German people.' This preceding introduction was important as it helped create an intergroup comparative context for this task; thus, ensuring compatibility with the Multi-Response Racial Attitude measure (MRA: Aboud, 2003; Doyle \& Aboud, 1995) that used a simultaneous presentation of in-group and out-group. The researcher then said: 'Let's talk about British people first/ now [depending upon order of administration]. Can you point to the card which shows how many British people are.... [trait].' Seven positive and seven negative traits were used. These adjectives were taken from the Preschool Racial Attitude Measure II (Pram II) Series A (Williams, Best, Boswell, \& Graves, 1975) or chosen after a small sample of 7- to 12-year-old children underwent an open-ended interview about their national intergroup attitudes. These traits were 'nice,' 'not nice,' 'kind,' 'unkind,' 'hardworking,' 'lazy,' 'clean,' 'dirty,' 'polite,' 'rude,' 'friendly,' 'unfriendly,' 'good,' and 'bad.' The order in which the child judged British and German people was counterbalanced. Each trait was gone through in turn and the order randomized for each child.

The ratings for British and German traits were subjected to separate reliability analyses and all proved reliable (Cronbach's alpha for British positive and negative traits $=0.78$ and 0.75 , respectively; for German positive and negative traits $=0.73$ and 0.75 , respectively). Given the satisfactory reliabilities, the ratings were collapsed to form single indices by calculating composite means resulting in four trait measures for each child - British positive, British negative, German positive and German negative. The higher the scores on positive indices the more positive the child's rating of the in-group or out-group. The higher the scores on negative indices the more negative the child's rating of the in-group or out-group. A relative positive trait bias score was computed by subtracting the German positive trait 
ratings from the British positive trait ratings. Thus, the higher the score the more positive bias the children showed towards the British relative to the Germans. A relative negative trait bias score was also calculated by subtracting the British negative trait rating from the German negative trait rating. In this case, the higher the score the more negative bias the children showed towards the Germans relative to the British. Finally, summing the relative positive and negative trait scores created an overall intergroup bias measure. The higher the intergroup trait bias score the more the children showed bias towards the British compared to the Germans in their positive and negative trait evaluations.

\section{Results}

The analyses conducted only involved one between-participants factor (namely, age group). Thus, problems created by unequal age group sizes are relatively minor (Howell, 2002; Tabachnick \& Fidell, 1996). Heterogeneity of variance and unequal sample sizes do not mix. If the group with the smaller $n$ has a larger variance, the $F$ test is too liberal, leading to increased Type 1 error rate and an inflated alpha level. Therefore, the degree of variance was checked in all ANOVA analyses (i.e., on the trait evaluation task and the affective rating task). In none of the analyses did the 11- to 12-year-old group have a larger $S D$. In addition, for each analysis the Levene test of equality of error variances was calculated (Howell, 2002). These Levene tests all proved non-significant indicating there was homogeneity of variance between the age groups on each measure. Therefore, the ANOVA assumption of homogeneity of variance was not violated in any of the analyses.

\section{Attribution of positive and negative traits}

To investigate age variations in trait bias, the children's ratings for positive and negative traits were submitted to a 4 (Age: $7,8,9,11-12$ years) $\times 2$ (Nation: British and German) $\times 2$ (Valence: positive and negative) ANOVA, with the last two variables being within participants. This ANOVA revealed main effects for Age $(F(3,101)=3.93, p<0.05)$, Nation $(F(1,101)=12.40, p<0.01)$, and Valence $(F(1,101)=149.06, p<0.001)$. Post hoc analyses showed that 7 -year olds made higher ratings overall than 8-year olds (Tukey HSD test, $p<0.05$ ) [7 years: $M=3.09, S D=0.22 ; 8$ years: $M=2.90$, $S D=0.25$; 9 years: $M=2.96, S D=0.23 ; 11-12$ years: $M=3.09, S D=0.21]$. The Nation main effect indicated an overall preference for the in-group $(M=3.08, S D=0.57)$ over the out-group $(M=2.94$, $S D=0.61)$ and the Valence main effect demonstrated the children scored higher on the positive $(M=3.59, S D=0.60)$ than the negative traits $(M=2.46, S D=0.58)$. However, these effects were qualified by the predicted interaction, Age $\times$ Nation $\times$ Valence $(F(3,101)=2.89, p<0.05)$. To examine this interaction further the children's ratings for positive and negative traits were separately submitted to a 4 (Age: 7, 8, 9, 11-12 years) $\times 2$ (nation: British and German) ANOVA, with the last variable being within participants. The ANOVA on ratings of positive traits found a main effect for Age $(F(1,101)=2.96, p<0.05)$ and Nation $(F(1,101)=26.97, p<0.001)$. Post-hoc analyses showed that 7-year olds made marginally higher ratings overall than 8-year olds (Tukey HSD test, $p<0.10$ ) [7 years: $M=3.80, S D=0.52 ; 8$ years: $M=3.45, S D=0.55$; 9 years: $M=3.53, S D=0.47 ; 11-12$ years: $M=3.45, S D=0.36$ ]. The main effect of Nation meant the children showed higher positive trait ratings for the British in-group overall $(M=3.76, S D=0.58)$ than the German out-group $(M=3.40$, $S D=0.62$ ). Evidence of significant national in-group bias is clear from Figure 1. Children of all ages showed this bias. Note also that scores for both in-group and out-group in each age group were either significantly or marginally higher than the midpoint of three, respectively (7-year olds: $t(30)=9.47$, $p<0.01, t(30)=4.69, p<0.01$; 8-year olds: $t(18)=4.44, p<0.01, t(18)=1.82, p<0.10$; 9-year olds: 


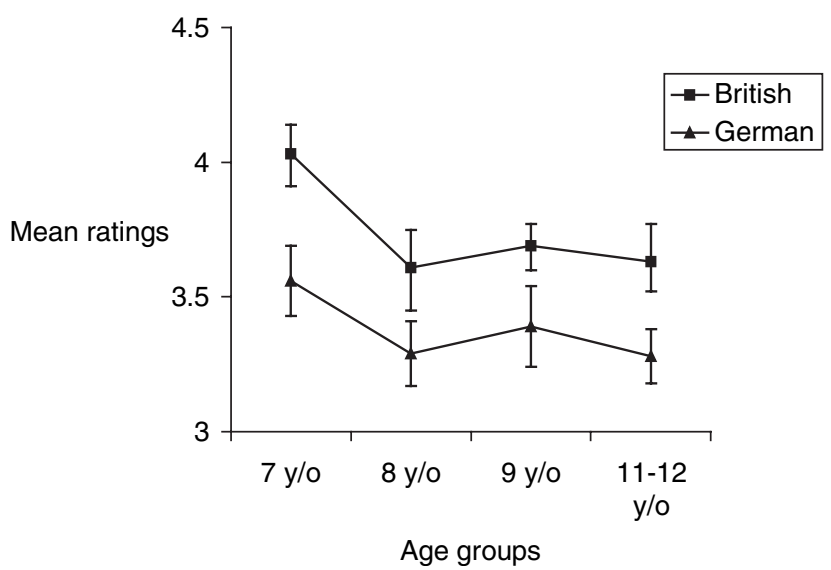

Figure 1. Mean ratings (and standard errors) of positive traits for the British in-group and German out-group amongst each age group

$t(39)=8.41, p<0.01, t(38)=4.13, p<0.01 ; 11$ - to 12 -year olds: $t(15)=4.61, p<0.01, t(16)=2.68$, $p<0.05)$. This is shown in Table 1 .

The ANOVA on the ratings of negative traits yielded the predicted significant interaction between Age and Nation $(F(3,101)=4.99, p<0.01)$. This interaction is shown in Figure 2. Simple effects within each age group revealed there was no significant difference between the negative trait ratings for Germans and British amongst the 8 -year olds $(t(18)=0.54$, n.s. $), 9$-year olds $(t(38)=-1.42$, n.s. $)$, and 11 - to 12 -year olds $(t(15)=0.13$, n.s. $)$. In contrast, the 7-year olds $(t(30)=-4.08, p<0.01)$ produced more negative trait ratings for Germans $(M=2.61, S D=0.72)$ than the British $(M=2.17, S D=0.45)$. Given that on the positive index all age groups revealed evidence of bias, this significant occurrence of bias on the negative index amongst the 7-year olds effectively means that they were unique in not showing the usual positive-negative asymmetry effect. Still, it should be noted that all ratings, for both in-group and out-group, respectively, were significantly lower than 3 for the 7-year olds $(t(30)=-10.40, \quad p<0.01 ; \quad t(30)=-3.01, \quad p<0.01), \quad 8$-year $\quad$ olds $\quad(t(18)=-4.48, \quad p<0.01 ;$ $t(18)=-4.07, p<0.01)$, and 9-year olds $(t(39)=-6.66, p<0.01 ; t(38)=-8.12, p<0.01)$. Amongst the 11 - to 12 -year olds in-group $(t(15)=-1.96, p<0.10)$ and out-group $(t(15)=-2.02, p<0.10)$ ratings were marginally lower than 3 . This is shown in Table 1 . Thus, levels of out-group prejudice were rather low in all age groups. Simple main effects within Nation revealed an age effect on British negative trait evaluations and a marginal age effect on German negative trait evaluations (British,

Table 1. Children's in-group and out-group positive and negative trait ratings in each age group

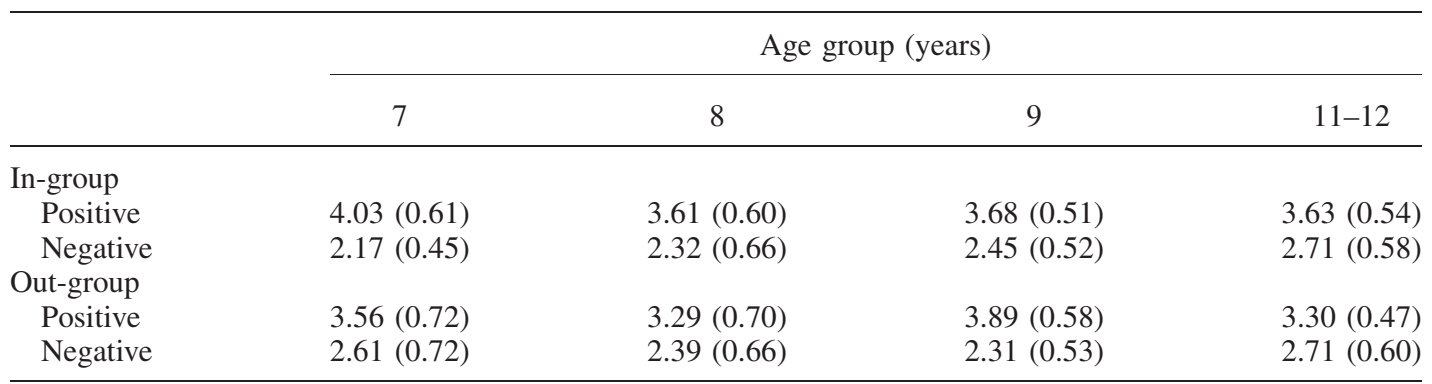




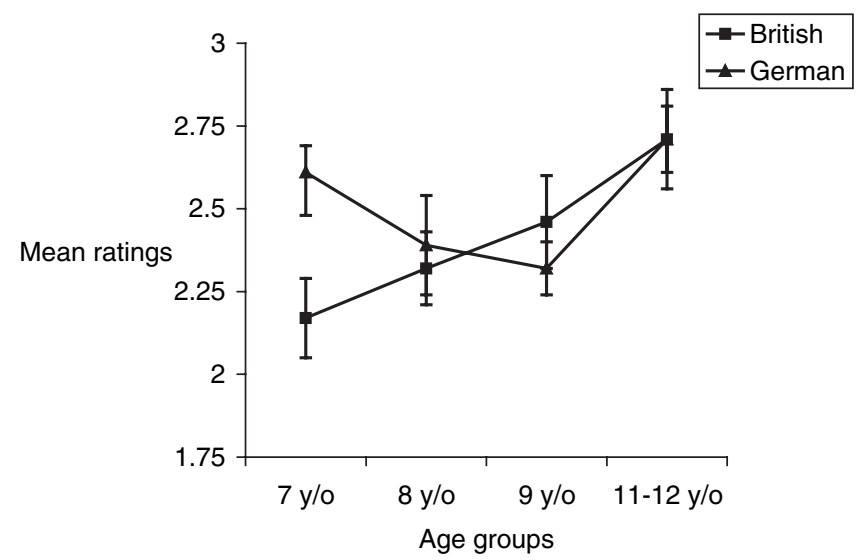

Figure 2. Study 1: Mean ratings (and standard errors) of negative traits for the British in-group and German outgroup amongst each age group

$F(3,105)=4.02, p<0.05$; German, $F(3,105)=2.23, p<0.10)$. Figure 2 and Table 1 indicate the age trend was linear in the case of the in-group ratings $\left(F_{\operatorname{Lin}}=3.38, p<0.01\right)$ and post-hoc analyses showed that 11- to 12-year olds $(M=2.71, S D=0.58)$ made more negative ratings than the 7-year olds $(M=2.17, S D=0.45$; Tukey HSD test, $p<0.01)$. In contrast, the age effect for the out-group target was a quadratic trend $\left(F_{\text {Quad }}=14.28, p<0.001\right)$. Post-hoc analyses showed no significant differences between out-group negative ratings across the age groups (Tukey HSD tests, $p>0.10$ ). Nonetheless, this quadratic trend is evident from Figure 2 and Table 1, where it can be seen that ratings of Germans decrease non-significantly amongst 8 - and 9 -year olds and then increase non-significantly amongst the 11- and 12-year olds.

\section{Intergroup bias}

The children's intergroup trait bias scores were submitted to a one-way ANOVA with age $(7,8,9,11-$ 12 years) as the independent variable. The ANOVA on intergroup trait bias found a significant effect for age $(F(3,104)=2.86, p<0.05)$ [ 7 years: $M=0.91, S D=1.11 ; 8$ years: $M=0.38, S D=1.04 ; 9$ years: $M=0.15, S D=1.67 ; 11-12$ years: $M=0.38, S D=1.22]$. As predicted, the age trend was quadratic $\left(F_{\text {Quad }}=2.77, p<0.01\right)$. Post-hoc analyses showed no significant differences between intergroup bias scores across the age groups (Tukey HSD tests, $p>0.10$ ), except the 7-year olds had significantly higher intergroup trait bias scores than 9-years olds (Tukey HSD test, $p<0.05$ ). In addition, only the ratings of the 7-year olds were significantly higher than the midpoint of 0 (one-sample $t$-tests significant at $p<0.05$ ). Thus, the quadratic age trend was due to a significant decrease in intergroup bias between 7 and 9 years, and then a non-significant increase amongst the 11- to 12-year olds.

\section{Discussion}

The findings of Study 1 indicate, as expected, a development trend in the 'positive-negative asymmetry' (PNAE: Mummendey \& Otten, 1998) with all the age groups, except the 7-year olds, 
showing intergroup bias in a dichotomous group context on the positive but not negative valence attributions. The 7-year olds showed clear-cut bias on the positive and negative attributions. Significantly, Study 1 demonstrated that even with dichotomous groups children aged above 7 years showed the PNAE by not discriminating on the attribution of negative outcomes. This finding suggests that evidence of the PNAE found by Bennett and colleagues (Bennett et al., 2004, 1998), when examining children's national intergroup attitudes probably did not result from their adoption of a multi-group context.

As anticipated, Study 1 also found a quadratic developmental trend in children's national intergroup bias, with bias being the highest amongst the 7-year olds then declining significantly until 9 years and increasing (though non-significantly) again at 11- to 12-years old. Most previous research (e.g., Aboud, 1988; Doyle \& Aboud, 1995; Yee \& Brown, 1992, 1994) has investigated children's attitudes towards ethnic, gender or artificial groups; it is thus noteworthy that we have observed a similar decrease in intergroup bias between 7 and 9 years with another socially significant category. It is important to note also that we have done so with measures that tapped evaluations of liking for in-group and out-group separately. Nonetheless, this quadratic trend in national intergroup bias is consistent with previous studies of national intergroup attitudes (e.g., Abrams et al., 2003a; Bennett et al., 1998; Rutland, 1999; Verkuyten, 2001) and the self-presentational account of prejudice development (Rutland, 2004; Rutland et al., 2005), which would predict an increase in national intergroup bias during early adolescence.

In line with SIT all age groups showed in-group bias. It is important to emphasize that, in line with other research (e.g., Aboud, 2003; Nesdale, 2004); little evidence of explicit derogation of the outgroup was found, even amongst the 7-year olds. At all ages, the children's evaluations/feelings were positive (or not negative) towards both in-group and out-group, only less positive (or more negative) towards the out-group. The mean ratings of the out-group seldom dipped below the midpoints of the scales and when they did, it was not a significant deviation (notably, it was the 7-year olds who showed this singular tendency). Of course, caution must be exerted in interpreting the scale midpoints too literally as indicating neutrality since the subjective interpretation of scales always depends on the meaning attributed to the anchor points. Nevertheless, one can still argue that the in-group bias observed here might not be wholly benign. In many everyday situations, children may be faced with a choice between interacting with (i.e., playing, talking, working) an in-group or out-group member. Manifestly, in these contexts 7- to 12-year olds in the Study 1 would prefer the in-group member. Thus, while clear prejudice towards the out-group may be absent, we should not underestimate the potential psychological harm this in-group bias may have on out-group targets.

\section{STUDY 2}

Study 1 successfully predicted a developmental trend in the PNAE based upon a developmental perspective of the normative account of the PNAE. Nonetheless, Study 1 did not examine directly any possible mechanisms involved in the development of the PNAE in children. Therefore, Study 2 was conducted to investigate whether normative processes mediated the development of the PNAE.

There is good reason to suggest that normative factors may underline the development of the PNAE. For example, Singh, Choo and Poh (1998) found that 7-year olds unlike older children failed to show the joint operation of in-group bias and fair-mindedness in their intergroup perceptions. It is possible that young children lack an internal motivation to control their intergroup bias on the negative dimension either because of the absence of a personal egalitarian motive to be fair minded or the failure to internalize the in-group social norm regarding the illegitimacy of any specific form of 
prejudice expression (Monteith, 1993; Plant \& Devine, 1998; Rutland, 2004; Rutland, et al., 2005). Indeed, the self-presentational account of prejudice development (Rutland, 2004; Rutland et al., 2005) suggests that children with age begin to control their social discrimination by conforming to perceived in-group social norms regarding the appropriateness of explicit negative intergroup bias (Crandall, Eshleman, \& O'Brien, 2002). Developmental research on children's evaluations of gender and racial exclusions also suggests that with age children develop social-conventional norms regarding the appropriateness of social exclusion (Killen \& Stangor, 2001; Killen et al., 2002). Therefore, Study 2 will examine whether with age children develop an increasing awareness of the in-group norm that the overt negative act of national exclusion (i.e., excluding German children from your activities because of their nationality) is unacceptable and that this mediates the children's attribution of negative traits to the British in-group and German out-group.

Significantly in Study 1 the children showed the PNAE using a within-subjects design. The majority of studies demonstrating the PNAE in adults have been conducted using between-subjects designs (Blanz et al., 1995; Otten et al., 1996), while the findings obtained in within-subject designs have not been similarly straightforward. For example, Wenzel and Mummendey (1996) found the PNAE only on 'pure' lists of traits, when participants evaluated the groups only with regard to either positive or negative traits (i.e., between-subjects). Wenzel and Mummendey (1996) argued that the mere existence of negative traits in a within-subjects design enhanced a fairness norm that reduced intergroup bias in general. In contrast, Otten and Wentura (2001) changed their response format to reduce the activation of such a fairness norm in a within-subjects design. Otten and Wentura (2001) also found the PNAE since, as in Study 1, the participants were presented with the traits trial-by-trial so they could see only one trait at a time. However, the emergence of the PNAE in Study 1 using a 'mixed' list of traits arguably may have resulted from the use of only antonyms as traits (e.g., kind, unkind). Consequently the children were either unwilling or unable to treat questions referring to the bipolar end-poles of a trait dimension as independent. Thus, in Study 2 the children will be presented with a list of traits which are not only antonyms on a trial-by-trial basis and asked to attribute each trait to either group or both groups. This response mode should ensure the children explicitly know that, for example, attributing a positive trait to in-group does not necessarily imply a negative trait must be assigned to the out-group.

\section{Method}

\section{Participants and Design}

Participants were 62 white British children (17 males and 45 females) from a predominately white middle-class suburban or rural area outside a large metropolitan city. Approximately 3-4\% of the school population was from a visible racial minority and a majority of the teachers were white British. Included were 236 - to 7-year-old children ( $M=7$ years 1 months; $S D=8$ months); 2010 - to 12-yearold children $(M=11$ years 0 months; $S D=7$ months); 1914 - to 16 -year-old children $(M=15$ years 2 months; $S D=15$ months).

\section{Procedure}

Children were given an in-group exclusion norm measure and a trait attribution task, administered in counterbalanced orders. The third author tested children individually in their schools. Previous research suggests that British children perceive negative exclusion based on a person's nationality as inappropriate (Rutland et al., 2005). To measure the children's awareness of this in-group norm they 
were presented with social exclusion vignettes. There were two versions of the vignettes with the content of the story and the genders of the characters varied to ensure gender relevance. In the male vignette, due to national group membership, British boys excluded two German boys from a soccer game. Similarly in the female vignette, British girls excluded two German girls from eating their school lunch (see Appendix for both vignettes). The selection of the vignettes was based upon a small-scale pilot study with 6- to 16-year-old participants. This showed that British children of all ages related to the activities described and the vignettes maintained their attention. Each vignette included three black and white line drawings presented with cartoon captions read by the third author, except among the 14- to 16-year olds since research suggests the use of cartoons does not maximize the attention of older children (e.g., Nucci, 1981). Instead adolescents were presented with typed event descriptions and asked to read these out loud to themselves.

Next the children were asked 'How bad do you think other British children would think the boys/ girls in the story were who wouldn't let the other children join in?' The 6- to 12-year-old children answered on a 4-point scale of smiley faces. The scale was: 'OK' (smiley face =1), 'bad' (little frown $=2$ ), 'very bad' (bigger frown $=3$ ), and 'very, very bad' (very big frown $=4$ ). The valence of the faces from left to right was counterbalanced. Smetana and colleagues (Smetana, 1981, Smetana \& Braeges, 1990; Smetana, Kelly, \& Twentyman, 1984) have used this scale previously when studying children's moral development. The choice of this scale also involved consideration of the developmental literature that suggests children are very likely to perceive instances of social exclusion as unacceptable (Killen \& Stangor, 2001; Killen et al., 2002; Rutland et al., 2005). Therefore, a scale was selected sensitive enough to identify possible variability in children's beliefs about the acceptability of negative social exclusion based on nationality. The 14- to 16-year-old adolescents answered using a simple 4-point numbered scale with the words (OK, bad, very bad, and very very bad) written below.

Unsurprisingly the children's responses to the question were skewed, with $7 \%$ responding ('OK'), $16 \%$ ('bad'), $40 \%$ ('very bad'), and 37\% ('very very bad'). This means that the assumption of multivariate normality has not been met and statistical inferences become less and less robust as distributions depart from normality (Bradley, 1982; Tabachnick \& Fidell, 1996). Therefore, we logtransformed the children's responses in order to use a statistic that has satisfactory stability of variance for analyses.

\section{Trait Attribution Measure}

The Multi-Response Racial Attitude (MRA) measure was used to derive separate indices of positive and negative attributions to the in-group and out-group (Aboud, 2003). The children were presented with 20 traits, 10 positive and 10 negative. These adjectives were taken from the Preschool Racial Attitude Measure II (Pram II) Series A (Williams et al., 1975). The positive adjectives were: 'clean,' 'wonderful,' 'healthy,' 'good,' 'nice,' 'happy,' 'friendly,' 'kind,' 'helpful,' and 'smart.' The negative adjectives were: 'unfriendly,' 'mean,' 'dirty,' 'cruel,' 'stupid,' 'selfish,' 'sick,' 'naughty,' 'sad,' and 'bad.' Unlike in Study 1, this trait list did not only use antonyms which arguably encouraged the children to treat the bipolar end-poles of a trait dimension as independent. To ensure the children understood the meaning of each word they were given a corresponding definition. Initially, children were presented with two copies of each word and two cups labeled 'British' and 'German.' The cups were also identified using simple gender-neutral cartoon faces. The children were explicitly told they could put the adjective in the 'German' cup, the 'British' cup or both cups. Thus ensuring the children explicitly knew that, for example, attributing a positive trait to in-group does not necessarily imply a negative trait must be assigned to the out-group. For instance, one item read, 'Some children are 
friendly. They often share their toys with other children. Who is friendly? Is it the German child, the British child or more than one child who is friendly.' To ensure understanding of the task, initially each child was asked to practice assigning adjectives by attributing four non-evaluative items to each of the categories (Black-Gutman \& Hickson, 1996). These items were 'likes to run,' 'likes to sing,' 'likes TV,' and 'likes music.'

The number of adjectives assigned to each cup was computed. Four scores were calculated; a positive and a negative trait score for each national group, each with a possible range of $0-10$. The higher the scores on positive traits and the higher the scores on negative traits the more positive and negative the child's ratings, respectively.

\section{Results and Discussion}

\section{Attribution of Positive and Negative Traits}

To investigate age variations in the attribution of positive and negative traits, the children's positive and negative ratings for positive and negative traits were submitted to a 3 (Age: 6-7, 10-12, 14-16 years $) \times 2$ (Nation: British and German $) \times 2$ (Valence: positive and negative) ANOVA, with the last two variables being within participants. This ANOVA revealed main effects for Age $(F(2$, $59)=5.64, p<0.01)$ and Nation $(F(1,59)=8.17, p<0.01)$. Post-hoc analyses showed the 6- to 7year-olds made fewer attributions overall than the 14- to 16-year olds (Tukey HSD test, $p<0.05$ ) [6-7 years: $M=7.64, S D=1.69 ; 10-12$ years: $M=8.68, S D=1.24 ; 14-16$ years: $M=9.07$, $S D=1.27]$. The Nation main effect indicated the children attributed more traits to the in-group $(M=8.61, S D=1.63)$ than the out-group $(M=8.21, S D=1.64)$. However, these effects were qualified by the predicted interaction, Age $\times$ Nation $\times$ Valence $(F(2,59)=3.83, p<0.05)$. To examine this interaction further the children's attributions of positive and negative traits were separately submitted to a 3 (Age: 6-7, 10-12, 14-16) $\times 2$ (Nation: British and German) ANOVA, with the last variable being within participants. The ANOVA on positive trait attribution only found a main effect for Nation $(F(1,59)=24.76, p<0.001)$. Evidence of significant national in-group bias was present with more positive trait attributions to the British in-group overall $(M=9.47$, $S D=1.50)$ than the German out-group $(M=7.56, S D=2.65)$. Again children in all age groups showed this bias.

The ANOVA on negative trait attributions found a main effect for $\operatorname{Age}(F(1,59)=7.48, p<0.01)$ and Nation $(F(1,59)=8.21, p<0.01)$. Post-hoc analyses showed the 6 - to 7 -year olds made fewer negative attributions overall than the 10-12 and 14-16 year olds (Tukey HSD tests, $p<0.05$ ) [6-7 years: $M=7.35, S D=1.61 ; 10-12$ years: $M=8.65, S D=1.52 ; 14-16$ years: $M=9.10, S D=1.48]$. The Nation main effect indicated the children attributed more negative traits to the out-group $(M=8.85, S D=1.77)$ than the in-group $(M=7.76, S D=2.62)$. However, these effects were qualified by the predicted significant interaction between Age and Nation $(F(2$, $59)=4.35, p<0.05)$. This interaction is shown in Figure 3. Simple effects within each age group revealed there was no significant difference between the negative trait attributions for the Germans and British amongst the 10 - to 12-year olds $(t(19)=-0.85$, n.s.) and 14- to 16-year olds $(t(18)=0.30$, n.s. $)$. In contrast, the 6- to 7-year olds $(t(22)=-3.28, p<0.01)$ attributed significantly more negative trait to the Germans $(M=8.57, S D=1.90)$ than the British $(M=6.13$, $S D=2.82$ ).

Given that on the positive attribution all age groups revealed evidence of bias, this significant occurrence of bias on the negative attributions amongst the 6- to 7-year olds effectively means that only 


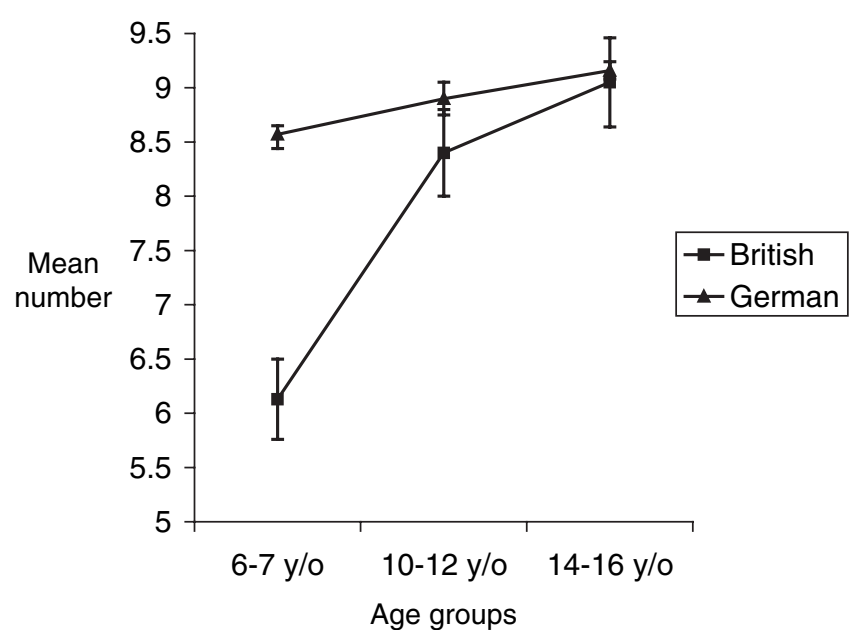

Figure 3. Study 2: Mean number of negative traits (and standard errors) attributed to the British in-group and German out-group amongst each age group

the two older age groups showed the usual PNAE. This finding replicates Study 1 which found that only the 7-year-old age group failed to show the PNAE. Study 2 also shows again that the PNAE may be found amongst older children with a 'mixed' list of traits, when children evaluate groups on a trial-bytrial basis with regard to both positive and negative traits (Otten \& Wentura, 2001). In addition, Study 2 also demonstrates that the PNAE is evident using a list of traits, which are not only antonyms, and when children are told explicitly they can attribute each trait to both groups. This suggests that the PNAE amongst older children is not because they are unable or unwilling to judge the positive and negative trait attributions independently.

\section{IN-GROUP EXCLUSION NORM AS A MEDIATOR}

Given the significant effect of age group on the children's attribution of negative traits, we went on to test the mediational role of in-group exclusion norm. Analysis had shown that only the 10- to 12-year-old and 14- to 16-year-old age groups showed the PNAE. Thus, to test our hypothesis an orthogonal contrast was constructed (age dummy). This tested the 6- to 7-year-old age group against the two other age groups (weights $-2,+1,+1$ ). Age trends were evident on the negative trait attributions, so a composite measure (negative attribution bias) was created by subtracting the number of negative traits attributed to the in-group from the number attributed to the out-group. Thus, the higher the score the more bias the children showed against the out-group in their negative trait attributions.

Multiple regression analyses were employed with the age dummy variable, the children's ratings on the in-group exclusion norm measure and their negative attribution bias scores. The age dummy variable had a significant bivariate relationship with the children's negative attribution bias scores ( $\beta=-0.35, p<0.01)$, which was reduced but still significant when the children's in-group exclusion norm scores were included in the model $(\beta=-0.26, p<0.05)$. According to the Sobel Test, as specified in Baron and Kenny (1986) (see also MacKinnon, Warsi, \& Dwyer, 1995), this reduction was marginally significant, $Z=-1.82, p=0.07)$. Finally, satisfying the criteria for partial mediation the 
Table 2. Interrelationships of variables

\begin{tabular}{lcccccc}
\hline Measure & 1. & 2. & 3. & 4. & 5. & 6. \\
\hline 1. Out-group positive attribution & - & 0.06 & 0.07 & $0.82^{* *}$ & $0.29^{*}$ & $0.32^{*}$ \\
2. In-group positive attribution & & - & $0.54^{* *}$ & 0.19 & -0.06 & 0.04 \\
3. Out-group negative attribution & & & - & 0.16 & -0.15 & 0.13 \\
4. In-group negative attribution & & & & - & $0.35^{* *}$ & $0.48^{* *}$ \\
5. In-group exclusion norm & & & & & - & $0.28^{*}$ \\
6. Age dummy $(-2,+1,+1)$ & & & & & - \\
\hline
\end{tabular}

Note: Numbers are Pearson's correlations $(r)$.

${ }^{*} p<0.05$.

${ }^{* *} p<0.001$.

children's in-group exclusion norm scores were significantly related to Age dummy $(\beta=0.28$, $p<0.05)$ and negative attribution bias $(\beta=-0.33, p<0.01)$. These findings indicate that the children's awareness of the in-group exclusion norm in part accounts for the relationship between age and the children's attribution of negative traits. It appeared children with age became increasing aware that overt negative national discrimination was unacceptable, which partially led in turn to less intergroup bias on their negative trait attributions. Correlations among continuous variables are shown for information in Table 2.

\section{GENERAL DISCUSSION}

In conclusion, taken together Study 1 and Study 2 showed there is a developmental trend in the PNAE, with 6- to 7-year-old children being the only age groups to express national intergroup bias on both positive and negative trait attributions. Both studies also indicated that children aged above 7 years showed the PNAE on 'mixed' trait lists. Noticeably, Study 2 demonstrated that children's awareness of the in-group exclusion norm partially mediated the development of the PNAE from middle childhood into adolescence. These findings provide empirical weight to an extended SIT account of this effect based upon normative factors (Amiot \& Bourhis, 2003, 2005a,b; Blanz et al., 1997; Mummendey \& Otten, 1998). This account suggests that around 7 years of age children typically become aware of an in-group norm regarding the unacceptability of national discrimination involving negative traits, and this partially, explains why older children then demonstrate the PNAE by only showing bias on positive trait attributions.

To our knowledge, Study 1 and Study 2 are the first studies to systematically investigate both the development of the PNAE through middle childhood into adolescence and an underlying mechanism involved in the onset of the PNAE. Previous studies have just documented that overall 6- to 11-year-old children typically show the PNAE (e.g., Bennett et al., 1998; Bigler et al., 2001), or that children aged between 3 and 5 years do not show the PNAE (Rutland et al., 2005). Bennett et al. (2004) did implicate social-politically embedded norms when providing post-hoc explanations for variations in the PNAE within a multi-national study of 6-year olds. Nonetheless, Bennett and colleagues were unable to do more than speculate about important mechanisms in the development of the PNAE since they did not examine an age range of children or measure the children's awareness of social-political norms or social representations prevalent in each society. In contrast, the present research was able to 
demonstrate the particular developmental path of the PNAE and the importance of in-group exclusion norms as a partial mediator of the effect.

However, the normative account would recognize that the development path of the PNAE may be different if our studies had used another national out-group (e.g., Australians) or an ethnic out-group (e.g., Afro-Caribbean). In-group norms regarding the unacceptability of attributing negative outcomes to these out-groups may have been stronger or more accessible in the historical and social context of our white British sample. Therefore, even the 6- to 7-year-old children may have shown the PNAE. Alternatively, in relation to gender intergroup attitudes there is some evidence that the differential allocation of negative outcomes is partly tolerated amongst children (e.g., Powlishta, Serbin, Doyle, \& White, 1994; Yee \& Brown, 1994). Therefore, in this context, the PNAE may not be evident in middle childhood. These are essentially empirical issues that could be resolved by further research. Nonetheless, while our studies indicate the importance of in-group norms in the development of the PNAE, it should be acknowledged that normative and ideological processes are not universal rather they are dependent on the socio-historical context. Norms and ideologies are not constant and fixed schemata pre-existing in any child head immune to the situational context (Amiot \& Bourhis, 2003, 2005a; Wenzel \& Mummendey, 1996).

Study 2 demonstrated that normative processes partially mediated the development of the PNAE when children in middle childhood express their national intergroup attitudes. This suggests further research should examine other important factors that might underline the development of the PNAE. There are essentially two main accounts of the PNAE apart from the normative account: the recategorization account (Gardham \& Brown, 2001; Mummendey \& Otten, 1998); and the cognitive account (Mummendey \& Otten, 1998; Otten, Mummendey, \& Buhl, 1998). The latter account suggests that in adults negative information receives more attention and weight than positive stimuli resulting in lengthier decision-making (Peeters, 1993; Pratto \& John, 1991). This more in-depth processing may reduce bias as participants realize the unjust nature of discrimination based upon arbitrary groups. Research based on the information processing approach to cognitive development indicates that young children have poor working memory and are less efficient at processing information (Case, 1985; Hitch \& Towse, 1995; Kail, 1990). This suggests young children may not have the processing ability to engage in lengthy decision-making and thus discriminate on both negative and positive outcomes. Future research should examine whether the cognitive account may explain the development of the PNAE.

The recategorization account emphasizes a recategorization process founded on a common fate experience, by which the in-group and out-group are recategorized into a more inclusive category (Gardham \& Brown, 2001; Mummendey \& Otten, 1998). Namely, when invited by researchers to engage in the counter-normative act of assigning negative outcomes, participants reactively recategorize the situation into 'us' (i.e., 'participants,' whether belonging to the 'in-group' or 'outgroup') and 'them' (i.e., 'researchers'). Such recategorization into a common in-group has been shown to reduce in-group bias especially in the negative area (see Gaertner \& Dovidio, 2000). Developmental research (e.g., Barenboim, 1981; Doyle \& Aboud, 1995; Livesley \& Bromley, 1973; Quintana, 1999) suggests children's ability to recategorize into more inclusive groupings may develop with age since only older children can simultaneously consider multiple and abstract classifications (i.e., individuating information, subordinate categories, superordinate categories). This would suggest, in line with the findings of Study 1 and 2, an emerging tendency to display the PNAE only from approximately 8 years of age; once children have developed the social-cognitive ability to consider multiple classifications and engage in recategorization.

However, the significance of a recategorization mechanism may be limited in the context of childadult relations and 'real' social groups (e.g., 'British,' 'German'). First, there is an essential asymmetry of power and status in child-adult relations, meaning children's social reasoning is typically 
heteronomous, namely their understanding is often one-sided and originates from external authority (Piaget, 1965). Therefore, children are less likely than adults to recategorize when asked by an adult to undertake a counter normative act. Second, Gardham and Brown (2001) suggest that recategorization becomes more difficult if contextual cues exist which highlight the salience of the original categories (i.e., 'British,' 'German'). Significantly, previous research suggests that amongst children there exists a context of a salient intergroup rivalry between Germany and Britain (see Abrams et al., 2003a; Barrett, et al., 2003; Rutland, 1999, 2004; Rutland et al., 2005), which may well discourage the recategorization process. Nonetheless, future research should investigate whether the recategorization account may help explain the development of the PNAE.

In-group identification could moderate the development of the PNAE in children, since previous research (Hodson, Dovidio, \& Esses, 2003; Mummendey, Otten, Berger, \& Kessler, 2000) suggests that in-group identification may moderate the PNAE in adults, with increases in identification resulting in greater social discrimination on positive but not negative outcomes. Developmental research indicates that children's social identification increases significantly in middle childhood (see Ruble, Alvarez, Bachman, \& Cameron, 2004), which might explain why older children in both Study 1 and 2 continued to discriminate on the positive trait attributions. In addition, identification may also influence the children's awareness of the in-group exclusion norm and, in turn their negative trait attributions. This is a possibility since Abrams et al. (2003a) demonstrated that children with low identification were less attentive than those with high identification to what is normative when engaging in social reasoning about inclusion and exclusion. Further studies are required to establish the possible mediating role of the recategorization process and the moderating function of in-group identification in the development of the PNAE.

Evidence of a developmental trend in the PNAE has potential implications for interventions designed to reduce intergroup bias in children. It suggests that amongst young children interventions should emphasize changing negative out-group evaluations, since this age group seems prone to expressions of bias in the negative evaluative domain. Interventions should also target bias based on positive evaluations, though these interventions might be more effective amongst older children. Prejudice reduction strategies based upon intergroup contact (Allport, 1954; Pettigrew \& Tropp, 2000) could provide one approach, given they provide opportunities for personal experience to change negative out-group evaluations (Cameron, Rutland, Brown, \& Douch, in press; Schofield \& EurichFulcer, 2001; Wright \& Tropp, 2005).

In conclusion, the findings of both studies go beyond previous research with children by showing a developmental path in the PNAE from middle childhood to adolescence and demonstrating the partial mediating role of in-group exclusion norms in the establishment of the PNAE. These findings provide support for the normative account of the PNAE within social psychology (Blanz et al., 1997; Mummendey \& Otten, 1998). Study 1 used 'mixed' trait lists in a dichotomous group context and successfully predicted developmental trends in the PNAE. As expected, the 7-year olds were the only age group not to show the PNAE. In line with the self-presentational account of prejudice development (Rutland, 2004; Rutland et al., 2005), Study 1 also found a quadratic developmental trend in children's national intergroup bias. Study 2 replicated the developmental path of the PNAE found in Study 1 using a 'mixed' list of traits which were not only antonyms and a procedure that meant children explicitly understood that the positive and negative trait dimensions were independent. Most importantly Study 2 also showed that developmentally children became increasing aware that overt negative national discrimination was unacceptable, which partially led in turn to less social discrimination on the negative traits. This finding indicates that the in-group exclusion norm is a partial mediator in the development of the PNAE. Future studies are required to identify further social and cognitive mechanisms involved in the development of response asymmetry in children's allocation of positive and negative outcomes. 


\section{REFERENCES}

Aboud, F. (1988). Children and prejudice. Oxford: Blackwell.

Aboud, F. E. (2003). The formation of in-group favoritism and out-group prejudice in young children: Are they distinct attitudes? Developmental Psychology, 39, 48-60.

Abrams, D., Rutland, A., \& Cameron, L. (2003a). The development of subjective group dynamics: Children's judgments of normative and deviant in-group and out-group individuals. Child Development, 74, 18401856.

Abrams, D., Rutland, A., Cameron, L., \& Marques, J. (2003b). The development of subjective group dynamics: When in-group bias gets specific. British Journal of Developmental Psychology, 21, 155-176.

Allport, G. W. (1954). The nature of prejudice. Cambridge, MA: Addison-Wesley.

Aloise-Young, P. A. (1993). The development of self-presentation: Self-promotion in 6 to 10 year old children. Social Cognition, 11, 201-222.

Amiot, C. E., \& Bourhis, R. Y. (2003). Discrimination and positive-negative asymmetry effect: Ideological and normative processes. Personality and Social Psychology Bulletin, 29, 597-608.

Amiot, C. E., \& Bourhis, R. Y. (2005a). Discrimination between dominant and subordinate groups: The positivenegative asymmetry effect and normative processes. British Journal of Social Psychology, 44, 289-308.

Amiot, C. E., \& Bourhis, R. Y. (2005b). Ideological beliefs as determinants of discrimination in positive and negative outcome distributions. European Journal of Social Psychology, 35, 581-598.

Banerjee, R., \& Lintern, V. (2000). Boys will be boys: The effect of social evaluation concerns on gender typing. Social Development, 9, 397-408.

Banerjee, R., \& Yuill, N. (1999a). Children's explanations for self-presentational behavior. European Journal of Social Psychology, 29, 105-111.

Banerjee, R., \& Yuill, N. (1999b). Children's understanding of self-presentational display rules: Associations with mental-state understanding. British Journal of Developmental Psychology, 17, 111-124.

Barenboim, C. (1981). The development of person perception in childhood adolescence: From behavioural comparisons to psychological constructs to psychological comparisons. Child Development, 52, 129-144.

Baron, R. M., \& Kenny, D. A. (1986). The moderator-mediator variable distinction in social psychological research: Conceptual, strategic, and statistical considerations. Journal of Personality and Social Psychology, 51, 1173-1182.

Barrett, M., Lyons, E., \& del Valle, A. (2004). The development of national identity and social identity processes: Do social identity theory and self-categorization theory provide useful heuristic frameworks for developmental research? In M. Bennett, \& F. Sani (Eds.), The development of the social self (pp. 159-188). East Sussex, England: Psychology Press.

Barrett, M., \& Short, J. (1992). Images of European people in a group of 5-10 year old English schoolchildren. British Journal of Developmental Psychology, 10, 339-363.

Barrett, M., Wilson, H., \& Lyons, E. (2003). The development of national in-group bias: English children's attributions of characteristics to English, American and German people. British Journal of Developmental Psychology, 21, 193-220.

Bennett, M., Barrett, M., Karakozov, R., Kipiani, G., Lyons, L., Pavlenko, V., \& Riazanova, T. (2004). Young children's evaluations of the ingroup and of outgroups: A multi-national study. Social Development, 13, 124141.

Bennett, M., Lyons, E. J., Sani, F., \& Barrett, M. (1998). Children's subjective identification with the group and ingroup favoritism. Developmental Psychology, 34, 902-909.

Bennett, M., \& Yeeles, C. (1990). Children's understanding of self-presentational strategies of ingratiation and self-promotion. European Journal of Social Psychology, 20, 455-461.

Bigler, R. S., Brown, C. S., \& Markell, M. (2001). When groups are not created equal: Effects of group status on the formation of intergroup attitudes in children. Child Development, 72, 1151-1162.

Bigler, R. S., Jones, L. C., \& Lobliner, D. B. (1997). Social categorization and the formation of intergroup attitudes in children. Child Development, 68, 530-543.

Black-Gutman, D., \& Hickson, F. (1996). The relationship between racial attitudes and social-cognitive development in children: An Australian Study. Developmental Psychology, 32, 448-456.

Blanz, M., Mummendey, A., \& Otten, S. (1995). Positive-negative asymmetry in social discrimination: The impact of stimulus-valence, size and status differentials in intergroup evaluations. British Journal of Social Psychology, 34, 409-419. 
Blanz, M., Mummendey, A., \& Otten, S. (1997). Normative evaluations and frequency expectations regarding positive versus negative outcome allocations between groups. European Journal of Social Psychology, 27, 165176.

Bradley, J. V. (1982). The insidious L-shaped distribution. Bulletin of the Psychonomic Society, 20, 85-88.

Brown, R. J. (1995). Prejudice: Its social psychology. Cambridge, MA: Blackwell.

Buhl, T. (1999). Positive-negative asymmetry in social discrimination: Meta-analytic evidence. Group Processes and Intergroup Relations, 2, 51-58.

Cameron, J. A., Alvarez, J. M., Ruble, D., \& Fuligni, A. J. (2001). Children's lay theories about in-groups and outgroups: Reconceptualizing research on prejudice. Personality and Social Psychology Review, 5, 118-128.

Cameron, L., Rutland, A., Brown, R. J., \& Douch, R. (in press). Changing children's intergroup attitudes towards refugees: Testing different models of extended contact. Child Development.

Case, R. (1985). Intellectual development: Birth to Adulthood. New York: Academic Press.

Crandall, C. S., Eshleman, A., \& O'Brien, L. (2002). Social norms and the expression and suppression of prejudice: The struggle for internalization. Journal of Personality and Social Psychology, 82, 359-378.

Doyle, A., \& Aboud, F. (1995). A longitudinal study of white children's racial prejudice as a social-cognitive development. Merrill-Palmer Quarterly, 41, 209-228.

Fazio, R. H., Jackson, J. R., Dunton, B. C., \& Williams, C. J. (1995). Variability in automatic activation as an unobstrusive measure of racial attitudes: A bona fide pipeline? Journal of Personality and Social Psychology, 69, 1013-1027.

Gaertner, S. L., \& Dovidio, J. F. (2000). Reducing intergroup bias: The common in-group identity model. Hove, East Sussex: Psychology Press.

Gardham, K., \& Brown, R. J. (2001). Two forms of intergroup discrimination with positive and negative outcomes: Explaining the positive-negative asymmetry effect. British Journal of Social Psychology, 40, 23-34.

Hartstone, M., \& Augoustinos, M. (1995). The minimal group paradigm: Categorization into two versus three groups. European Journal of Social Psychology, 25, 179-193.

Hitch, G. J., \& Towse, J. (1995). Working memory: What develops? In F. E. Weinert, \& S. Schneider (Eds.), Memory performance and competencies: Issues in growth and development. Hillsdale, NJ: Erlbaum.

Hodson, G., Dovidio, J. F., \& Esses, V. M. (2003). Ingroup identification as a moderator of positive-negative asymmetry in social discrimination. European Journal of Social Pscyhology, 33, 215-233.

Howell, D. C. (2002). Statistical methods for psychology (5th ed.). Pacific Grove, CA: Duxbury.

Johnson, N. (1973). Development of English children's concept of Germany. Journal of Social Psychology, 90, 259-267.

Kail, R. (1990). The development of memory in children (3rd ed.). New York: Freeman.

Katz, P. A. (1976). The acquisition of racial attitudes in children. In P. A. Katz (Ed.), Towards the elimination of racism (pp. 125-154). New York: Pergamon.

Katz, P. A., Sohn, M., \& Zalk, S. R. (1975). Perceptual concomitants of racial attitudes in urban grade-school children. Developmental Psychology, 11, 135-144.

Killen, M., Lee-Kim, J., McGlothlin, H., \& Stangor, C. (2002). How children and adolescents evaluate gender and racial exclusion. Monographs for the society for research in child development (Serial No. 271, Vol. 67, No. 4). Oxford, England: Blackwell Publishers.

Killen, M., \& Stangor, C. (2001). Children's social reasoning about inclusion and exclusion in gender and race peer group contexts. Child Development, 72, 174-186.

Lambert, W. E., \& Klineberg, O. (1967). Children's views of foreign peoples: A cross-national study. New York: Appleton-Century-Crofts.

Livesley, W. J., \& Bromley, D. B. (1973). Person perception in childhood \& adolescence. Oxford; John Wiley \& Sons.

MacKinnon, D. P., Warsi, G., \& Dwyer, J. H. (1995). A simulation study of mediated effect measures. Multivariate Behavioral Research, 30, 41-62.

Monteith, M. J. (1993). Self-regulation of prejudiced responses: Implications for progress in prejudice-reduction efforts. Journal of Personality and Social Psychology, 65, 469-485.

Mummendey, A., Klink, A, \& Brown, R. (2001). Nationalism and patriotism: National identification and out-group rejection. British Journal of Social Psychology, 40, 159-172.

Mummendey, A., \& Otten, S. (1998) Positive-negative asymmetry in social discrimination. In W. Streobe, \& M. Hewstone (Eds.), European review of social psychology (Vol. 9, pp. 107-143). Chichester: John Wiley \& Sons Ltd. 
Mummendey, A., Otten, S., Berger, U., \& Kessler, T. (2000). Positive-negative asymmetry in social discrimination: Valence of evaluation and salience of categorization. Personality and Social psychology Bulletin, 26, 12581270.

Mummendey, A., Simon, B., Dietze, C., Grünert, M., Haeger, G., Kessler, S., Lttgen, S., \& Schäferhoff, S. (1992). Categorization is not enough: Intergroup discrimination in negative outcome allocation. Journal of Experimental Social Psychology, 28, 125-144.

Nesdale, D. (2001). Development of prejudice in children. In M. Augoustinos, \& K. J. Reynolds (Eds.), Understanding prejudice, racism and social conflict (pp. 57-72). London: Sage.

Nesdale, D. (2004). Social identity processes and children's ethnic prejudice. In M. Bennett, \& F. Sani (Eds.), The development of social self (pp. 219-245). East Sussex, England: Psychology Press.

Nucci, L. (1981). Conceptions of personal issues: A domain distinct from moral or societal concepts. Child Development, 52, 114-121.

Otten, S., Mummendey, A., \& Blanz, M. (1996). Intergroup discrimination in positive-negative outcome allocations: The impact of stimulus valence, relative group status and relative group size. Personality and Social Psychology Bulletin, 22, 568-581.

Otten, S., Mummendey, A., \& Buhl, T. (1998). Information processing and social discrimination: Accuracy in information processing and positive-negative asymmetry in social discrimination. Revue Internationale de Psychologie Sociale, 2, 69-96.

Otten, S., \& Wentura, D. (2001). Self-anchoring and in-group favoritism: An individual profiles analysis. Journal of Experimental Social Psychology, 37, 525-532.

Peeters, G. (1993). The positive-negative asymmetry: On cognitive consistency and positivity bias. European Journal of Social Psychology, 23, 455-474.

Pettigrew, T. F., \& Tropp, L. R. (2000). Does intergroup contact reduce prejudice: Recent meta-analytic findings. In S. Oskamp (Ed.), Reducing prejudice and discrimination 'The Claremont Symposium on Applied Social Psychology’ (pp. 93-114). Mahwah, NJ, US: Lawrence Erlbaum Associates, Publishers.

Piaget, J. (1965). The moral judgment of the child. New York: Free Press.

Plant, E. A., \& Devine, P. G. (1998). Internal and external motivation to respond without prejudice. Journal of Personality and Social Psychology, 75, 811-832.

Powlishta, K., Serbin, L. A., Doyle, A., \& White, D. R. (1994). Gender, ethnic, and body type biases: The generality of prejudice in childhood. Developmental Psychology, 30, 526-536.

Pratto, F., \& John, O. P. (1991). Automatic vigilance: The attention-grabbing power of negative social information. Journal of Personality and Social Psychology, 61, 380-391.

Quintana, S. M. (1999). Role of perspective-taking abilities and ethnic socialization in development of adolescent ethnic identity. Journal of Research on Adolescence, 19(2), 161-184.

Ruble, D. N., Alvarez, J., Bachman, M., \& Cameron, J. (2004). The development of a sense of 'We': The emergence and implications of children's collective identity. In M. Bennett, \& F. Sani (Eds.), The development of social self (pp. 29-76). East Sussex, England: Psychology Press.

Rutland, A. (1999). The developmental of national prejudice, in-group favoritism and self-stereotypes in British children. British Journal of Social Psychology, 38, 55-70.

Rutland, A. (2004). The development and self-regulation of intergroup attitudes in children. In M. Bennett, \& F. Sani (Eds.), The development of the social self (pp. 247-265). East Sussex, England: Psychology Press.

Rutland, A., Cameron, L., Bennett, L., \& Ferrell, J. (2005). Interracial contact and racial constancy: A multi-site study of racial intergroup bias in 3-5 year old Anglo-British children. Journal of Applied Developmental Psychology, 26, 699-713.

Rutland, A., Cameron, L., Milne, A., \& McGeorge, P. (2005). Social norms and self-presentation: Children's implicit and explicit intergroup attitudes. Child Development, 76, 451-466.

Rutland, A., \& Cinnirella, M. (2000). Context effects on Scottish national and European self-categorization: The importance of category accessibility, fragility and relations. British Journal of Social Psychology, 39, 495-519.

Schofield, J. W., \& Eurich-Fulcer, R. (2001). When and how desegregation improves intergroup relations. In R. J. Brown \& S. Gaertner (Eds.), Blackwell's handbook of social psychology: Intergroup processes (pp. 475-494). Oxford: Blackwell.

Singh, R., Choo, W. M., \& Poh, L. L. (1998). In-group bias and fair-mindedness as strategies of self-presentation in intergroup perception. Personality and Social Psychology Bulletin, 24, 147-162.

Smetana, J. G. (1981). Preschool children's conceptions of moral and social rules. Child Development, 52, 13331336.

Smetana, J. G., \& Braeges, J. L. (1990). The development of toddlers' moral and conventional judgments. MerrillPalmer Quarterly, 36, 329-346. 
Smetana, J. G., Kelly, M., \& Twentyman, C. T. (1984). Abused, neglected, and nonmaltreated children's conceptions of moral and social-conventional transgressions. Child Development, 55, 277-287.

Tabachnick, B. G., \& Fidell, L. S. (1996). Using multivariate statistics. New York: Harper Collins College Publishers.

Tajfel, H., Nemeth, C., Jahoda, G., Campbell, J. D., \& Johnson, N. (1970). The development of children's preference for their own country: A cross-national study. International Journal of Psychology, 5, 245-253.

Tajfel, H., \& Turner, J. C. (1986). The social identity theory of intergroup behaviour. In S. Worchel, \& W. G. Austin (eds.), The psychology of intergroup relations (pp. 7-24). Chicago: Nelson-Hall.

Takriti, R., Buchanan-Barrow, E., \& Barrett, M. (2000). Children's perceptions of their own and one other religious group. Poster to be Presented at the XVIth Biennial Meeting of the International Society for the Study of Behavioral Development, Beijing, China, July 2000.

Teichman, Y. (2001). The development of Israeli children's images of Jews and Arabs and their expression in human figure drawings. Developmental Psychology, 37, 749-761.

Verkuyten, M. (2001). National identification and intergroup evaluations in Dutch children. British Journal of Developmental Psychology, 19, 559-571.

Verkuyten, M. (2003). Ethnic in-group bias among minority and majority early adolescents: The perception of negative behaviour. British Journal of Developmental Psychology, 21, 543-564.

Wenzel, M., \& Mummendey, A. (1996). Positive-negative asymmetry of social discrimination: A normative analysis of differential evaluations of the in-group and out-group on positive and negative attributes. British Journal of Social Psychology, 35, 493-507.

Wilder, D. A. \& Thompson, J. E. (1988). Assimilation and contrast effects in the judgements of groups. Journal of Personality and Social Psychology, 54, 62-73.

Williams, J. E., Best, D. L., Boswell, D. A., Mattson, L. A., \& Graves, D. J. (1975). Preschool racial attitude measure II. Educational and Psychological Measurement, 35, 3-18.

Wright, S., \& Tropp, L. (2005). Language and intergroup contact: Investigating the impact of Bilingual instruction on children's intergroup attitudes. Group Processes and Intergroup Relations, 8, 309-328.

Yee, M. D., \& Brown, R. (1992). Self-evaluation and intergroup attitudes in children aged three to nine. Child Development, 63, 619-629.

Yee, M. D., \& Brown, R. (1994). The development of gender differentiation in young children. British Journal of Social Psychology, 33, 183-196.

\section{APPENDIX}

\section{Vignettes used to measure in-group exclusion norm}

\section{Female version}

It was lunchtime and three girls were at a school dining table eating their lunch. There were two extra seats at the table. Next Marie and Katharina, who were German girls, came up to the girls and asked if they could sit down beside them in the extra seats. The girls said no to Marie and Katharina, and explained that they do not like mixing with German people. This upset Marie and Katharina.

\section{Male version}

One day, in the school ground, three boys wanted to play a 5-a-side soccer game. However, they could not because they needed two extra boys. Next Jonas and Lukas, who were German boys, came up to the boys and asked if they could join in. The boys said no to Jonas and Lukas, and explained that they do not like playing with German people. This upset Jonas and Lukas. 